\title{
A case of severe anaphylaxis after Ropalidia marginata (a paper wasp) sting in Sri Lanka
}

Witharana EWRA ${ }^{1}$, Karunaratne WAIP ${ }^{2}$, Gnanathasan $\mathrm{A}^{3}$, Wijesinghe $\mathrm{SKJ}^{4}$, Kadahetti $\mathrm{SCL}^{5}$,

\section{Introduction}

Ants, bees and wasps are insects in Order Hymenoptera. Victims of Hymenoptera sting can present with nuisance pain to more severe form of anaphylaxis [1]. Ropalidia marginata (Kaladuruwa) is the most common social wasp of Peninsula of India [2]. Traditional medication is a common practice in rural Sri Lanka for insect sting. Nest of the Ropalidia marginata is crushed and mixed with water to make a paste which is applied on the painful area over the stinging site of paper wasp as a common traditional treatment.

Although there are many cases of allergic reactions after wasp sting, the individual species of Ropalidia marginata causing severe anaphylaxis is not reported. We report a school boy presented with severe anaphylaxis after this paper wasp sting in Deniyaya, Sri Lanka.

\section{Case report}

Twelve years old boy was admitted to the Base Hospital in Deniyaya, with anaphylaxis after stinging by paper wasps on 09/08/2013. He was stung while he was sitting near a small bridge at about 5.00 pm observing road renovation work. The surrounding area was mostly disturbed by road reconstruction activities. Immediately after the wasp attack the child had felt intense pain over legs and hands (right knee, left index finger, left second toe and left ankle). Few minutes after the incident, patient complained generalised itching associated with erythematous rash and facial puffiness. The child had vomited once and felt dizzy. He has no history of bronchial asthma, allergic rhinitis, urticaria, eczema, or allergy to food or drugs. He has never had wasp sting in the past.

On admission his blood pressure was not recordable and pulse was undetectable. He had a generalised urticarial rash and facial puffiness suggestive of severe allergic reaction. Immediately after the investigation the child was treated with intra muscular Adrenalin, fluid bolus, intravenous Hydrocortisone and Chlorpheniramine.

1,4,5 Base Hospital, Deniyaya,

${ }^{2}$ Department of Zoology, University of Peradeniya,

${ }^{3}$ Department of Clinical Medicine, University of Colombo

(Index words: Hymenoptera, Ropalidia marginata, anaphylaxis)
Patient made an immediate recovery.

White cell count was $7800 / \mathrm{mm} 3$ with $57 \%$ of Neutrophils, $40 \%$ of Lymphocytes, $1 \%$ of Monocytes and $2 \%$ of Eosinophils. Haemoglobin was $11.6 \mathrm{~g} / \mathrm{dl}$ and platelet count was $244000 \mathrm{~mm} 3$. Renal and liver functions were all normal. The patient was closely observed for four days in the hospital. Two days after the incident small ulcers (1-2cm diameter) which were surrounded by an erythematous area appeared over the stinging site.

Interestingly father of the child brought the specimens of offending wasp which was found under surface of the small bridge. We further surveyed the area and found many wasp nests hanging from the bridge with live paper wasps (Figure 1a and 1b). The wasp was identified as Ropalidia marginata.

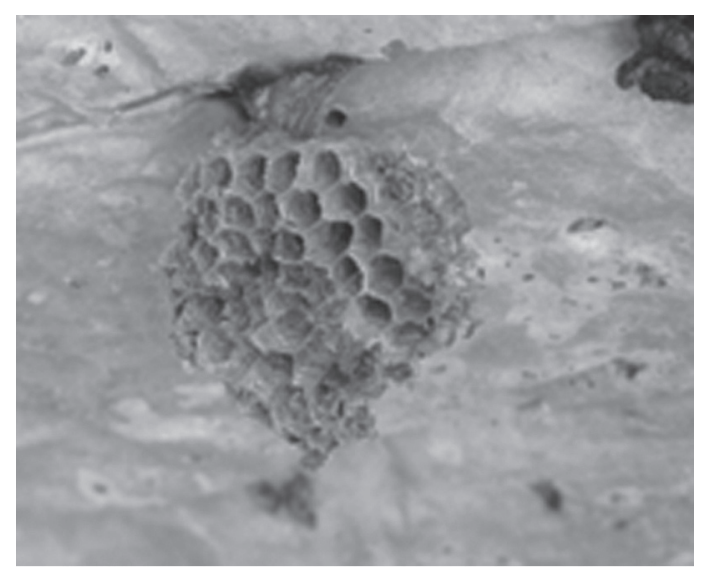

Figure 1. (a). Ropalidia marginata abandoned nest and

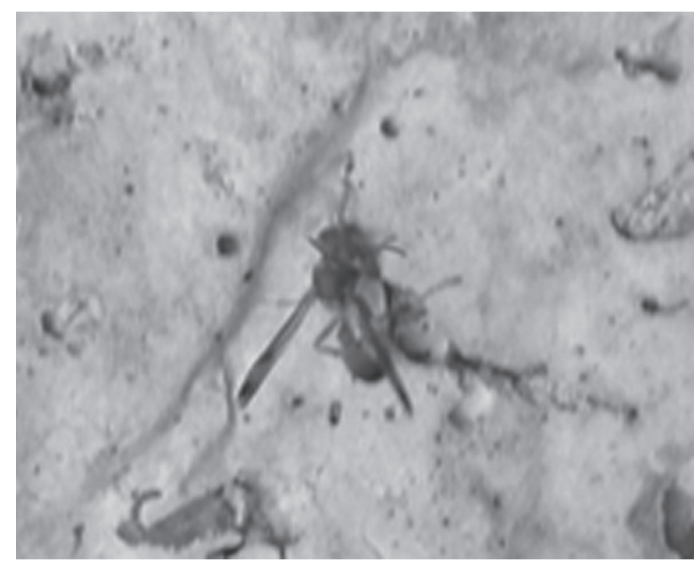

Figure 1. (b). Live specimen of Ropalidia marginata resting under surface of the bridge 


\section{Discussion}

Nests of Ropalidia marginata consists of a single open comb that can have sometimes up to 500 cells. Most common number of individual wasps per nest is 1-4 [2]. The stinging apparatus of female hymenopterans is called stinger which is a modified ovipositor located at the tip of their abdomen associated with a venom gland [3]. Active components of wasp venom are serotonin, histamine, tyramine, catecholamines, wasp kinins and histamine-releasing peptides [4]. They use those toxins for defence when they are disturbed.

Well known complications of wasp sting include multi organ failure, myocardial infarction, hepato-renal failure and rhabdomyolysis [4,5]. Urticaria, angioedema, allergic conjunctivitis, allergic asthma and anaphylaxis are common immunological reactions to Hymenoptera venom [3]. Our patient had severe anaphylaxis due to Ropalidia marginata sting. Anaphylaxis is common in patient who has history of allergy, asthma or past history of hymenoptera sting, but our patient has no history of similar conditions. Severe allergy after Hymenoptera sting is not an uncommon problem in rural Sri Lanka. So hospitals should be ready with emergency treatment for anaphylaxis as it is life threatening.

\section{References}

1. Theodore M, Freeman MD. Hypersensitivity to Hymenoptera Stings. New England Journal of Medicine. 2004; 351:1978-1984.

2. Gadagkar R, Gadgil M, Joshi NV, Mahabal AS, Observations on the natural history and population ecology of the social wasp Ropalidia marginata from Peninsula India, Proceedings of the Indian academy of Sciences (Animal Sciences), 1982, 91:539-552.

3. Gruchalla RS. Immunotherapy in allergy to insect stings in children. New England Journal of Medicine. 2004; 351 (7):707-709.

4. Vetter RS, Visscher PK, Camazine S. Mass envenomations by honey bees and wasps. Western Journal of Medicine. 1999; 170: 223-7.

5. Kularatne SAM, Gawarammana IB, De Silva PHJG. Severe multi organ dysfunction following multiple wasp (Vespa affinis) stings. Ceylon Medical Journal. 2003; 48 (4):146-147. 